\title{
Hasat Sonrası Salisilik Asit Uygulamalarının “Roxana” Kayısı Çeşidinin Muhafazası Süresince Aroma Bileşenlerine Etkisi
}

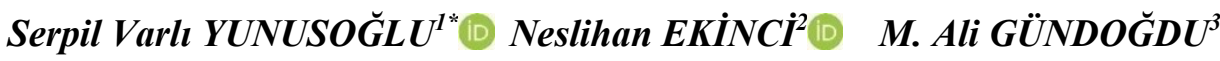 \\ 1,2,3 Çanakkale Onsekiz Mart Üniversitesi, Ziraat Fakültesi, Bahçe Bitkileri Bölümü̈, Çanakkale/ TURKEY
}

\author{
${ }^{I}$ https://orcid.org/0000-0001-5699-0507 2 ${ }^{2}$ https://orcid.org/0000-0001-7022-5289 \\ ${ }^{3}$ https://orcid.org/0000-0002-5802-5505 \\ *Corresponding author (Sorumlu yazar): srpl.varli@gmail.com
}

Received (Geliş tarihi):23.08.2021Ａccepted (Kabul tarihi): 22.11 .2021

\begin{abstract}
ÖZ: Bu çalışma, hasat sonrası salisilik asit (SA) uygulamalarının "Roxana" kayısı çeşidinin muhafazası süresince aroma bileşenlerine etkisinin belirlenmesi amacıyla yürütülmüştür. Çalışmada, hasat edilen meyvelerde üç farklı dozda (0,5, 1 ve $2 \mathrm{mM}$ ) salisilik asit uygulaması yapılmış ve uygulama yapılmamış kontrol grubu meyvelerle karşılaştırılmıştır. Çalışma grubundaki bütün meyveler 1 gün ön soğutma işlemine tabi tutulmuş ve $0 \pm 0,5^{\circ} \mathrm{C}$ sicaklıkta ve $\% 90 \pm 5$ oransal nem içeren normal atmosfer koşullarında 45 gün süresince soğuk hava deposunda muhafaza edilmiştir. Araştırmada hasattan sonra başlangıç analizleri ile birlikte 15 günlük aralıklarla suda çözünebilir kuru madde miktarı (\% SÇKM), titre edilebilir toplam asitlik (\% malik asit) ve aroma bileşen kompozisyonu parametreleri incelenmiştir. Yapılan çalışmada $2 \mathrm{mM}$ salisilik asit uygulaması tüm kriterlerde ön plana çıkmış ve meyvelerin olgunlaşma hızını diğer uygulamalara göre yavaşlatmıştır. Çalışmada incelenen "Roxana" kaylsı çeşidine ait meyvelerde aldehit, ester, keton, lakton, alkol ve terpen aroma bileşen gruplar tespit edilmiştir. Kayısı meyvelerinin karakteristik aromasına katkı sağlayan bileşen gruplarından lakton ve esterlerde, 1 ve 2 mM SA uygulamaları bu aroma bileşenlerinin olması gereken düzeyde sentezlenmesine katkı sağlamıştır. Ester aroma bileşen grubunda yer alan ve kayısı meyvesi için majör aroma bileşenlerinden olan hekzil asetat bileşeni başlangıçta 332,1 değerinde tespit edilmiş ve olgunluğun ilerlemesiyle miktarında artış gerçekleşmiştir. 15 günlük muhafaza periyodunun sonunda hekzil asetat bileşeninde en yüksek artış kontrol uygulamasında iken, 45 günlük muhafaza süresinin sonunda en yüksek değer 579,9 değeri ile 2 mM salisilik asit uygulamasında tespit edilmiştir.
\end{abstract}

Anahtar Kelimeler: Prunus armeniaca L., salisilik asit, soğukta muhafaza, aroma bileşenleri.

\section{The Effect of Post-Harvest Salicylic Acid Applications on Aroma Components During the Storage of the "Roxana" Apricot Cultivar}

\begin{abstract}
This study was carried out to determine the effects of postharvest salicylic acid (SA) applications on aroma components during the storage of "Roxana" apricot variety. In the study, salicylic acid at three different doses (0.5, 1 and $2 \mathrm{mM}$ ) was applied to the harvested fruits and compared with the untreated control group fruits. All fruits in the study group were pre-cooled for 1 day and stored in cold storage for 45 days under normal atmospheric conditions at $0 \pm 0.5^{\circ} \mathrm{C}$ and $90 \pm 5 \%$ relative humidity. In the research, soluble solid content (\% SSC), titratable total acidity (\% malic acid) and aroma component composition parameters were investigated at 15-day intervals, together with the initial analysis after harvest. In the study, $2 \mathrm{mM}$ salicylic acid application came to the fore in all criteria and slowed down the ripening rate of fruits compared to other applications. Aldehyde, ester, ketone, lactone, alcohol and terpene aroma component groups were determined in the fruits of the "Roxana" apricot cultivar examined in the study. It was found that 1 and 2 mM SA applications in lactones and esters, which are component groups that contribute to the characteristic aroma of apricot fruits, contributed to the synthesis of these aroma components at the required level. Hexyl acetate component, which is in the ester aroma component group and is one of the major aroma components for apricot fruit, was initially determined at a value of 332.1 and its amount increased with the progression of maturity. At the end of the 15-day storage period, the highest increase in hexyl acetate component was detected in the control group, while the highest value was determined in the application of $2 \mathrm{mM}$ salicylic acid with a value of 579.9 at the end of the 45-day storage period.
\end{abstract}

Keywords: Prunus armeniaca L., salicylic acid, cold storage, aroma components. 


\section{GİRIŞ}

Sert çekirdekli meyve türleri arasında yer alan kayıs1 (Prunus armeniaca L.), Rosales takımı Rosaceae familyas1, Prunus cinsi Prunophoraa alt cinsinde yer almaktadır. Kayısının ana vatanı Çin, Orta Asya ve Yakın Doğu olarak bilinmektedir. Türkiye sahip olduğu coğrafi konumu sebebiyle birçok meyve tür ve çeşidinin yetiştiriciliğinin yapılmasına imkan sağlamaktadır. Türkiye'de Karadeniz Bölgesi ile kışları uzun ve soğuk geçen Doğu Anadolu Bölgesi'nin dağlık alanları dışında, birçok yerinde kayısı yetişebilmektedir. Ülkemizdeki kayısı üretiminin büyük çoğunluğu Malatya ilinde gerçekleştirilmektedir. (Özbek, 1978). 2019 FAO istatistik verilerine göre dünyada 4.083.861 ton kayısı üretimi gerçekleştirilmektedir (Anonim, 2019). 2020 TÜİK verilerine göre de Türkiye 833,398 ton kayısı üretimi gerçekleştirerek dünya kayısı üretiminde lider konumundadır (Anonim, 2020). Bununla birlikte ülkemiz kuru kayıs1 ihracatında üstünlüğünü korumaktadır. Ancak, yaş kayısı üretim miktarı göz önünde bulundurulduğu zaman, yaş kayısı ihracat oranımız oldukça düşüktür. Bunun sebebi kayısı meyvesinin hassas olması nedeniyle taşımaya elverişli olmamas1 ve bununla paralel hasat sonras1 ömrünün kısıtlı olmasıdır. Bu amaçla hasat sonrası dayanımını, dolayısıyla muhafaza ömrünü artırmak amacıyla çalışmalar devam etmektedir. Deneme kapsamında kullanılan 'Roxana"' kayısı çeşidi son dönemde tüketimi ve ihracatı artan bir çeşittir. Geç dönemde olgunlaşan bir çeşit olduğu için muhafaza edilerek, kayısının pazardaki arzını uzun süre sağlayabilme potansiyeline sahiptir.

Kayısı meyvesi tat, aroma ve albeni bakımından tüketici tarafindan talep edilen klimakterik bir meyve türüdür (Asma, 2000). Bahçe ürünlerinin, özellikle klimakterik meyve türlerinin, hasat sonrası fizyolojisi bakımından, derimden sonraki tazeliğinin korunması, türe en uygun şekilde olgunlaştırılması ve depolama sürelerini uzatacak en uygun önlemlerin alınarak tüketiciye ulaştırılması, sağlıklı bir muhafaza süreci için zorunludur (Fidan ve Söylemezoglu, 1995). Birçok fiziksel, kimyasal ve biyokimyasal değişimleri içeren fizyolojik bir süreç olan olgunlaşma ile meyvelerin lezzeti ve albenisi artar. Olgunlaşma ile birlikte meyvelerde renk değişimi, meyve etinin yumuşaması, tat değişimi (şekerin artıp organik asit miktarının azalması) ve aroma bileşenlerinin artması gibi fiziksel ve biyokimyasal değişimler ve hücresel olarak da hücre duvarında incelme, hücreler arası boşluklarda ve hücre zarı geçirgenliğinde artış gibi değişimler gerçekleşir (Beattie ve Wade, 2001; Martinez-Romero ve ark., 2007). Meyve etinin yeşilden sarıya dönmeye başladığ döneminde hasat edilen kayısı meyveleri, taşıma, nakliye ve depolama için daha uygundur. $\mathrm{Bu}$ nedenle, hemen tüketim için uygun olmayan dönemde erken hasat edilmektedir. Erken hasat, tüketiciler arasında meyvelerin lezzeti konusunda memnuniyetsizlik yaratmaktadır. Klimakterik meyvelerin hasattan sonra olgunlaşmaya devam etmesi nedeniyle, meyve kalitesi tüketici için kabul görebilir bir olgunluk seviyesine ulaşabilmektedir (Reid, 1992).Ürünlerdeki ilk satın alımlar dış görünüş ve meyve eti sertliğine dayalıdır. Ancak meyvelerdeki aroma eksikliği, bir sonraki satın alımları etkilemektedir (Seker ve ark., 2018).

Kayıs1 zengin aroma profiline sahip olmas1 sebebiyle tüketiciler tarafindan beğenilmektedir. $\mathrm{Bu}$ aroma profilleri meyve çeşidi, olgunluk aşaması ve yetiştiricilik yapılan bölgenin iklimi ve yetiştiricilik aşamasında yapılan kültürel işlemler ile yakından ilişkilidir. Ek olarak hasat sonrası yapılan uygulamalar ve muhafaza koşulları da aroma profilini ve konsantrasyonunu etkileyen etmenlerdir (Baldwin, 2002; Şeker ve ark., 2012). Meyvelerde tat ve aroma bileşenlerinin oluşumu oldukça karmaşık bir biyokimyasal süreçtir. Meyveye özgü aromatik bileşenlerin oluşumu erken dönemde gerçekleşmez, olgunluğun ilerlemesi ile karakteristik aromatik bileşenleri sentezlenmeye başlar. $\mathrm{Bu}$ sentez sırasında, metabolik değişimler sonucu katabolik değişimler meydana gelmektedir. Sonuç olarak uçucu aroma bileşenleri değişik biyokimyasallar yollar ile ana bileşenlerden meydana gelebilmektedir (Perez ve ark., 1992). Meyvelerin kendine özgü aroma bileşenleri tüketiciler tarafından kabul görmesinin en önemli nedenlerinden biridir. İçlerinde kayısı da olmak üzere, genel anlamda meyvelerin aroma bileşiklerinin 
konsantrasyonları düşük seviyelerdedir. Kayısı çeşitleri için genel olarak belirlenmiş başlıca aroma bileşikleri ise aldehitler, alkoller, esterler, terpenler ve asitlerdir (Deflippi ve ark., 2009). Bu bileşikler arasinda etil asetat, hekzil asetat, limonen, 6-metil5-hepten-2-on, menton, E-hekzen-2-al, linalool, $\beta$ iyonon ve $\gamma$-dekalakton Türkiye'nin belli başlı tüm kayısı çeşitlerinde bulunmaktadır (Gokbulut ve Karabulut, 2011; Seker ve ark., 2018).

Kayısının yaş üretim ve ihracatı ülkemiz için ekonomik açıdan önemlidir. Bu sebeple kaliteli meyveye olan talep artmıştır. $\mathrm{Bu}$ amaçla kayısının hasat sonrası dayanım süresinin uzatılması üzerine çalışmalar devam etmektedir. Son yıllarda gıda güvenliği önemli konuların başında geldiği için, hasat sonrası dayanım süresini uzatırken, insan sağlığına zararı olmayan uygulamalar yapılması oldukça önemlidir. Fenolik bileşikler grubunda yer alan ve hormon olarak da kabul edilen salisilik asidin en belirgin özelliği etilen üretimini inhibe ederek yaşlanmayı geciktirmesidir. Bununla birlikte salisilik asit bitkilere dişsal olarak uygulandığı zaman, patojen bağlantılı proteinlerin sentezini teşvik ederek, hastalıklara karșı dayanıklılık sağlamaktadır (Özeker, 2005). Ayrıca poligalaktronaz, pektinmetilesteraz gibi bazı enzimlerin aktivitesini azaltmakta, yumuşamayı engellemektedir. Ek olarak meyve rengi ve tat bileşenleri gibi birçok kalite özelliklerini de muhafaza ettiği bilinmektedir (Srivastava ve Dwivedi, 2000). Kayıs1 meyvelerinde hasattan sonra muhafaza sürecinin kalite özellikleri ile birlikte aroma bileşenlerine etkileri üzerinde yeterli çalışma bulunmamaktadır. $\mathrm{Bu}$ kapsamda bu araştırma, bir organik asit olan salisilik asit ile insan sağlığına herhangi bir zararı olmadan kayısı meyvelerinin muhafaza ömrünü uzatabilmek ve bununla birlikte muhafaza süresince aroma bileşenlerinde meydana gelen değişimleri değerlendirmek amaciyla yürütülmüştür.

\section{MATERYAL ve YÖNTEM}

\section{Bitki materyali}

Araştırmada bitkisel materyal olarak "Roxana" kayısı çeşidine ait, ticari hasat döneminde toplanan meyveler kullanılmıştır. "Roxana" çeşidi geç dönemde olgunlaşmakla beraber, son dönemlerde taze tüketim ve ihracat için yetiştiriciliği artmıştır (Asma ve ark., 2006). Yayvan büyüyen ve kuvvetli ağaçlara sahip olup, erken verime yatar ve orta şiddette verimlidir. Meyve kabuk rengi sarı zemin üzerinde koyu turuncu renkte olup, meyve eti turuncu ve 80 ile $120 \mathrm{~g}$ ağırlığa sahiptir (Çalhan, 2010). Araştırma amaciyla hasat edilen meyveler, Çanakkale ili merkez ilçeye bağlı Yapıldak köyüne ait arazide özel üreticiye ait bahçeden alınmış olup, arazi 40.138815 kuzey enlemi, 26.526146 doğu boylamında bulunmaktadır. "Roxana" kayısı çeşidi ağaçları 12 yaşında olup, tam verim çağındadır. Meyve ağaçlarında goble terbiye şekli verilmiştir. Gübreleme toprak ve yaprak tahlili göz önüne alınarak gerçekleştirilmiş olup; sulama, ilaçlama gibi kültürel işlemler düzenli olarak yapılmaktadır. Meyvelerin derimi elle yapılmış olup, meyve sapından yavaşça döndürülerek hasat edilmiştir. Hasat edilen meyveler Çanakkale Onsekiz Mart Üniversitesi Ziraat Fakültesi Bahçe Bitkileri Laboratuvarına getirilmiş ve bir örnek materyal olacak şekilde ayıklanmıştır. Sert olum döneminde toplanmış ve ortalama 65-85 g olan meyveler muhafaza edilecek meyve materyallerini oluşturmaktadır.

\section{Uygulama materyali}

Bir örnek olacak şekilde seçilen meyveler uygulama yapmak üzere tesadüfi olacak şekilde 4 gruba ayrılmıştır. Çalışmanın uygulama materyali organik asit olan salisilik asittir. Meyveler salisilik asidin 0 (Kontrol), 0.5, 1 ve $2 \mathrm{mM}$ dozları uygulanmak üzere gruplandırılmıştır. Söz konusu dozları içeren solüsyonlara $10 \mathrm{dk}$ süre ile daldırma yapılmıştır. Kontrol grubu ise $10 \mathrm{dk}$ süre ile saf suya daldırılmıştır. Yayıcı yapıştırıcı olarak \%0,01'lik Tween 20 kullanılmıştır. Daldırma işleminden sonra meyveler üzerindeki fazla suyu buharlaştırmak amacıyla $30 \mathrm{dk}$ oda koşullarında kurumaya bırakılmıştır.

1) $10 \mathrm{dk}$ süre ile saf su uygulaması (Kontrol)

2) $10 \mathrm{dk}$ süre ile $0,5 \mathrm{mM} \mathrm{SA}$ uygulamas1

3) $10 \mathrm{dk}$ süre ile $1 \mathrm{mM} \mathrm{SA}$ uygulamas

4) $10 \mathrm{dk}$ süre ile $2 \mathrm{mM} \mathrm{SA}$ uygulamas 
Meyvelere uygulama yapıldıktan hemen sonra 1 gün hava ile ön soğutma uygulanmıştır. Çalışma kapsamında meyveler $0 \pm 0,5{ }^{\circ} \mathrm{C}$ sicaklıkta ve $\% 90 \pm 5,0$ oransal nem koşullarında 45 gün süreyle muhafaza edilmiştir. Araştırma 15 günlük periyotlarda kalite ve aroma analizleri gerçekleştirilmiştir. Muhafaza süresi boyunca soğuk hava depoları manuel olarak nemlendirilmiş ve her gün $10 \mathrm{dk}$ süre ile manuel olarak havalandırılmıştır.

\section{Suda çözünebilir toplam kuru madde miktarı (\%)}

Sert olum döneminde hasadı yapılan "Roxana" kayısı çeşidine ait 15 adet meyveden üç tekerrürlü olmak üzere, her tekerrürde beş adet meyvenin her birinden ayrı ayrı, meyve suyunun içindeki toplam suda çözünebilir kuru madde el refraktometresi ile ölçülmüştür.

\section{Titre edilebilir toplam asitlik (\%)}

Meyveler bir homojenizatör yardımı ile parçalanmıştır. Homojen meyve püresinden elde edilen meyve suyundan $10 \mathrm{ml}$ örnek alınmıș ve saf su ile 50 ml'ye tamamlanmıștır. Bu çözelti, manyetik karıștırıcı ve dijital pH-metre kullanılarak 0.1 normal $\mathrm{NaOH}$ ile $\mathrm{pH} 8.1$ oluncaya kadar titre edilmiștir. Harcanan $\mathrm{NaOH}$ miktarı aşağıdaki formüle konarak hâkim organik asit (malik asit) \% olarak hesaplanmıştır.

S: Harcanan baz miktarı (ml)

N: Harcanan bazın normalitesi

F: Harcanan bazın faktörü

E: Asidin equvalent değeri (malik asit $=0.067$ )

C: Örnek miktarı (ml)

\section{Meyve kabuk rengi}

Meyvelerin meyve kabuk rengi, meyvenin ekvator bölgesinde; her iki yanaktan okuma şeklinde yapılmıştır. Ölçümler her muhafaza döneminde aynı meyvelerde yapılmıştır. L* ve $\mathrm{Hue}^{\mathrm{o}}$ renk değerleri "Minolta CR 400 chromameter" aletiyle ölçülmüştür.

\section{Duyusal analiz}

Duyusal değerlendirmeler için Koyuncu ve ark. (2005)'nın bildirdikleri skala değerleri kullanılmıştır.
Meyvelerin tat ve aroma değeri için 1-5 skalası ve dış görünüş değeri için 1-9 skalasından yararlanılmıştır. Tat ve Aroma Skalası; 1: Çok kötü, 2: Kötü, 3: Orta, 4: İyi, 5: Çok iyi.

Dış Görünüş Skalası; 1-3: Pazarlanamaz, 5: Pazarlanabilir, 7: İyi, 9: Çok iyi.

\section{Meyvelerdeki aroma bileşenlerinin belirlenmesi}

Ticari olgunluk döneminde hasadı yapılan "Roxana" kayısı çeşidine ait meyvelerde uçucu bileşenlerin tanımlanması ve miktar tayini Seker ve ark. (2018) tarafindan belirtilen yöntem kullanılarak, Shimadzu QP2010 Plus GC-MS cihazında gerçekleştirilmiştir. Örneklerin analize hazırlanması (ekstraktsiyon) aşaması şu şekildedir: Homojenizatör ile elde edilen meyve pürelerinden $50 \mathrm{~g}$ örnek erlenmayer içinde $100 \mathrm{ml}$ dietil eter çözgeni ile muamele edilmiş ve çözücü $1 \mathrm{ml}$ 'ye santrifüj ve konsantratör yardımıyla derişikleştirilmiştir. GC/MS cihazının çalışma koşulları ise aşağıda verilmiştir:

Taşıyıcı Gaz: Helyum

Kolon: DB-WAX® polyethylene glycol (PEG) $(30 \mathrm{~m} \times 0,25 \mathrm{~mm} \times 0,25 \mu \mathrm{m})$

Enjeksiyon bloğu sicaklığ $280{ }^{\circ} \mathrm{C}$

Doğrusal akış: $41 \mathrm{~cm} / \mathrm{sn}$

Basınç: 70,3 kPa

Enjeksiyon modu: Split (1:50)

Fırın sıcaklık programı: Başlangıçta $40{ }^{\circ} \mathrm{C}$ ' de $1 \mathrm{dk}$, sonra $4{ }^{\circ} \mathrm{C} / \mathrm{dk}$ hiz ile $60{ }^{\circ} \mathrm{C}$ 'de $1 \mathrm{dk}$, akabinde $4{ }^{\circ} \mathrm{C} / \mathrm{dk}$ hiz ile $200{ }^{\circ} \mathrm{C}$ 'de $2 \mathrm{dk}$ en sonunda $10^{\circ} \mathrm{C} / \mathrm{dk}$ hız ile $250^{\circ} \mathrm{C}$ 'de $10 \mathrm{dk}$ şeklindedir.

Toplam analiz süresi 59 dakikadır.

Dedektör: Kütle spektrometresi (MS)

Kütüphane: Nist ve Wiley

İyon sıcaklığı: $250{ }^{\circ} \mathrm{C}$

İnterfaz sıcaklığ $1: 230{ }^{\circ} \mathrm{C}$

Solvent Cut Time: $4 \mathrm{dk}$

Taranan kütle aralığı: 40-350 amu (m/z)

Tarama hizı: $666 \mathrm{amu} / \mathrm{sn}$

İyonizasyon enerjisi: $70 \mathrm{eV}$ 


\section{İstatistiksel analizler}

Çalışma Tesadüf Blokları Deneme Deseni'ne göre yürütülmüş ve her tekerrürde 65-85 g meyvelerden 10 adet alınarak yukarıda bahsedilen uygulamalar gerçekleştirilmiştir. Verilerin analizi iki yönlü varyans analizi ile yapılmış ve farklı ortalamaların belirlenmesinde Asgari Önemli Fark (AÖF) çoklu karşılaştırma testi kullanılmıştır. Hesaplama ve yorumlarda önem düzeyi (p) $\% 5$ olarak dikkate alınmıştır. Verilerin istatistik analizleri $\mathrm{SAS}^{\circledR}$ (ver.9) istatistik paket program ile yapılmıştır. Biplot grafikler Minitab ver. 16 istatistik programı tarafından tasarlanmıştır.

\section{BULGULAR ve TARTIŞMA}

Meyvelerde aroma bileşenlerinin üretimi, tüketici memnuniyetini sağlamak için duyusal olarak da tamamlayıcı olan önemli bir faktördür. Araştırma sonucunda "Roxana" kayısı çeşidine ait meyvelerde dört adet aldehit, beş adet alkol, yedi adet ester, üç adet keton, dört adet lakton ve bir adet terpen olmak üzere toplam 24 adet uçucu bileşen altı farklı aroma bileşen grubunda tanımlanmıştır (Çizelge 3).

Araştırma kapsamında tanımlanan (Z)-3-Hekzenal, Hekzanal, Benzaldehit, (E)-2-Hekzenal bileşikleri aldehit grubunda; Hekzanol, E-2-Hekzenol, 2Propanol, 1-Butanol ve Etanol Alkol grubunda; Butil butilat, Hekzil asetat, İzobütil bütanoat, Metil asetat, Butil asetat, Metil bütanoat, Z-3-Hekzenil asetat bileşikleri ester grubunda; 6-Metil-5-hepten2 -on, Dihidro- $\beta$-iyonon, $\beta$-İyonon bileşikleri keton grubunda; $\gamma$-Nonalakton, $\quad \gamma$-Dekalakton, $\quad \gamma$ Oktalakton, $\delta$-Dekalakton lakton grubunda ve limonen bileşeni ise terpen grubunda tespit edilmiştir (Çizelge 3 ).

Ticari olum döneminde hasat edilen meyvelerde yapılan ölçümlerde, alkoller arasında yer alan 2Propanol, 1-Butanol dişındaki tüm bileşenler araştırma başlangıcında tespit edilmiştir. 2-Propanol, 1-Butanol olgunlaşmanın başlaması ile beraber 15 . günden sonra tanımlanmıştır (Çizelge 3).

"Roxana" kayısı çeşidine ait meyvelerde hasat sonrası SA uygulamasının muhafaza süresi boyunca kalite kriterlerine olan etkisi Çizelge 1 ve
Çizelge 2'de verilmiştir. Denemede farklı dozlarda SA uygulamasının "Roxana" kayısı çeşidinde depolama süresince meyve kabuk renginde meydana gelen $\mathrm{L}^{*}$ değeri değişimleri incelendiğinde uygulamalar ve muhafaza süresinin ortalamaları istatistiksel açıdan $(p<0,05)$ önemli bulunmuştur. Çalışmada muhafaza süresinin sonunda genel anlamda tüm uygulamalarda $L^{*}$ değerinde düşüş meydana gelmiştir. $2 \mathrm{mM} \mathrm{SA}+\mathrm{MAP}$ ve $1 \mathrm{mM}$ $\mathrm{SA}+\mathrm{MAP}$ uygulamalarının başlangıçtaki $\mathrm{L}^{*}$ değerlerini korumada etkili olduğu görülürken, diğer uygulamaların meyvelerinde $\mathrm{L}^{*}$ değerinde düşüşler saptanmıştır (Çizelge 1). Yaşar (2017), çalışmasında kiraz meyvesinin $\mathrm{L}^{*}$ değerini korumada SA'nın en etkili dozlarının sırasıyla 1 $\mathrm{mM}$ ve 2 mM'lık dozları olduğunu bildirmiştir. Renk ölçümlerinde hue değeri ele alındığında, muhafaza süresi hue ${ }^{0}$ değeri üzerinde önemli bir faktör olmuştur. Muhafaza süresinin uzaması meyve eti renginin yeşilden sariya ve daha sonra sarı-turuncuya dönmesine neden olmuştur. Genellikle renk çemberinde hue ${ }^{\circ}$ değeri 100 'ün üzerindeyse meyvenin yeşil rengini, $80-90$ arası değerlerde seyrediyorsa meyvenin sar1 rengini ve 70-80 arasında olduğu zamanda meyvenin sarı-turuncu rengini ifade etmektedir (Anonymous, 1998).

Çizelge 1 incelendiğinde hasattan sonra başlangıç analizlerinde $0,14 \mathrm{~g} / 100 \mathrm{ml}$ olan TEA değeri tüm uygulamalarda muhafaza süresinin uzamasiyla 30 . güne kadar düşüş gerçekleştirmiş, 45. günde ise artış tespit edilmiştir. Bu sonuçlar, "Roxana" kayısı çeşidinde farklı depolama koşullarının, çeşidin muhafaza süresine etkisinin incelendiği bir çalışmanın sonuçlarıyla paralellik göstermektedir (Çalhan, 2010). Muhafaza süresince TEA değerlerindeki azalmanın, solunum sırasında organik asitlerin kullanılmasından kaynaklanabilmektedir (Dundar ve ark., 1997; Özkaya ve ark., 2005). Muhafaza süresinin SÇKM miktarına etkisi ise, ortalamalar incelendiğinde muhafaza süresi ile doğru orantılı olarak SÇKM miktarında artış şeklinde ortaya çıkmıştır. Depolama süresindeki artışın yaşlanma ve olgunlaşmaya neden olması ile meyvede buna bağlı olarak meydana gelen su kaybı SÇKM oranının artmasına neden olabilmektedir (Özdemir ve ark., 2006; Sakaldaş, 2012; Erbaş ve ark., 2015). Başlangıçta \%7.56 değerinde ölçülen 
Çizelge 1. "Roxana" kayısı çeşidine ait meyvelerde hasat sonrası SA uygulamalarının muhafaza süresi boyunca meyvelerde kabuk rengi $\left(\mathrm{L}^{*}, \mathrm{Hue}^{\mathrm{o}}\right)$, titre edilebilir asitlik ve suda çözünür katı madde değerlerinin değişimlerine etkisi.

Table 1. The effect of post-harvest SA applications on changes in skin color $\left(\mathrm{L}^{*}\right.$, Hue $\left.{ }^{\circ}\right)$ titratable total acidity and soluble solid content values in fruits of "Roxana" apricot cultivar during the storage period.

\begin{tabular}{|c|c|c|c|c|c|c|}
\hline \multirow{8}{*}{$\begin{array}{c}\text { Meyve kabuk } \\
\text { rengi }\left(\mathrm{L}^{*}\right) \\
\text { Fruit skin } \\
\text { color }\left(\mathrm{L}^{*}\right)\end{array}$} & $\begin{array}{l}\text { Uygulama } \\
\text { Application }\end{array}$ & $\begin{array}{l}\text { 0. Gün } \\
\text { Day } 0\end{array}$ & $\begin{array}{l}\text { 15. Gün } \\
\text { Day } 15\end{array}$ & $\begin{array}{l}\text { 30. Gün } \\
\text { Day } 30\end{array}$ & $\begin{array}{l}\text { 45. Gün } \\
\text { Day } 45\end{array}$ & $\begin{array}{c}\text { Ortalama } \\
\text { Average }\end{array}$ \\
\hline & KONTROL & 51,19 & 46,82 & 44,45 & 40,11 & $45,64 \mathrm{~A}$ \\
\hline & $0,5 \mathrm{SA}$ & 46,28 & 46,50 & 45,65 & 43,13 & $45,39 \mathrm{~A}$ \\
\hline & $1 \mathrm{SA}$ & 45,12 & 44,36 & 44,03 & 41,18 & $43,67 \mathrm{~A}$ \\
\hline & $2 \mathrm{SA}$ & 43,59 & 42,57 & 40,59 & 38,15 & $41,23 \mathrm{~B}$ \\
\hline & Ortalama / Average & $46,55 \mathrm{~A}$ & $45,06 \mathrm{AB}$ & $43,68 \mathrm{~B}$ & $40,64 \mathrm{C}$ & $\cdots$ \\
\hline & LSD $^{*}$ & \multicolumn{4}{|c|}{2.3983} & 2.3983 \\
\hline & $\begin{array}{l}\text { LSD p }<0,05 \\
\text { (UygXSüre) }\end{array}$ & \multicolumn{5}{|c|}{ Ö.D. } \\
\hline \multirow{9}{*}{$\begin{array}{c}\text { Meyve kabuk } \\
\text { rengi }\left(\mathrm{Hue}^{\mathrm{o}}\right) \\
\text { Fruit skin } \\
\text { color }\left(\mathrm{Hue}^{\mathrm{o}}\right)\end{array}$} & Uygulama & 0. Gün & 15. Gün & 30. Gün & 45. Gün & Ortalama \\
\hline & Application & Day 0 & Day 15 & Day 30 & Day 45 & Average \\
\hline & KONTROL & $72,74 \mathrm{Ba}^{*}$ & $70,62 \mathrm{Ca}$ & $67,85 \mathrm{Ba}$ & $66,24 \mathrm{Ba}$ & $69,36 \mathrm{C}$ \\
\hline & $0,5 \mathrm{SA}$ & $97,86 \mathrm{Aa}$ & $95,46 \mathrm{Aa}$ & $79,77 \mathrm{Ab}$ & $77,30 \mathrm{Ab}$ & $87,60 \mathrm{~B}$ \\
\hline & $1 \mathrm{SA}$ & $104,50 \mathrm{Aa}$ & $99,14 \mathrm{Aa}$ & $84,06 \mathrm{Ab}$ & $80,66 \mathrm{Ab}$ & $92,09 \mathrm{~A}$ \\
\hline & $2 \mathrm{SA}$ & $96,10 \mathrm{Aa}$ & $87,76 \mathrm{Bb}$ & $84,06 \mathrm{Ab}$ & $83,09 \mathrm{Ab}$ & $87,76 \mathrm{AB}$ \\
\hline & Ortalama / Average & $92,80 \mathrm{~A}$ & $88,25 \mathrm{~B}$ & $78,94 \mathrm{C}$ & $76,82 \mathrm{C}$ & $=$ \\
\hline & LSD $^{*}$ & \multicolumn{4}{|c|}{4,3411} & 4,3411 \\
\hline & $\begin{array}{l}\text { LSD p }<0,05 \\
\text { (UygXSüre) }\end{array}$ & \multicolumn{5}{|c|}{7,2983} \\
\hline \multirow{9}{*}{$\begin{array}{c}\text { Titre edilebilir } \\
\text { toplam asitlik } \\
\text { (malik asit \%) } \\
\text { Titratable total } \\
\text { acidity (malic } \\
\text { acit \%) }\end{array}$} & Uygulama & 0. Gün & 15. Gün & 30. Gün & 45. Gün & Ortalama \\
\hline & Application & Day 0 & Day 15 & Day 30 & Day 45 & Average \\
\hline & Kontrol & $0,14 \mathrm{Ab}$ & $0,11 \mathrm{Bc}$ & $0,09 \mathrm{Bc}$ & $0,17 \mathrm{Aa}$ & 0,13 \\
\hline & $0,5 \mathrm{SA}$ & $0,14 \mathrm{Ab}$ & $0,11 \mathrm{ABc}$ & $0,10 \mathrm{ABc}$ & $0,16 \mathrm{Aa}$ & 0,13 \\
\hline & $1 \mathrm{SA}$ & $0,14 \mathrm{Aa}$ & $0,12 \mathrm{ABb}$ & $0,12 \mathrm{Ab}$ & $0,14 \mathrm{Ba}$ & 0,13 \\
\hline & $2 \mathrm{SA}$ & $0,14 \mathrm{Aa}$ & $0,13 \mathrm{Aa}$ & $0,11 \mathrm{Ab}$ & $0,13 \mathrm{Ca}$ & 0,13 \\
\hline & Ortalama / Average & $0,14 \mathrm{~A}$ & $0,12 \mathrm{~B}$ & $0,11 \mathrm{~B}$ & $0,15 \mathrm{~A}$ & -------- \\
\hline & LSD $^{*}$ & \multicolumn{4}{|c|}{0.0112} & Ö.D. ${ }^{* *}$ \\
\hline & $\begin{array}{l}\text { LSD p }<0,05 \\
\text { (UygXSüre) }\end{array}$ & \multicolumn{5}{|c|}{0,0138} \\
\hline \multirow{9}{*}{$\begin{array}{l}\text { Suda çözünür } \\
\text { kuru madde }(\%) \\
\text { Soluble solid } \\
\text { content }(\%)\end{array}$} & Uygulama & 0.Gün & 15. Gün & 30. Gün & 45. Gün & Ortalama \\
\hline & Application & Day 0 & Day 15 & Day 30 & Day 45 & Average \\
\hline & Kontrol & 7,56 & 8,71 & 9,41 & 11,56 & $9,31 \mathrm{~A}$ \\
\hline & $0,5 \mathrm{SA}$ & 7,56 & 8,66 & 9,30 & 11,03 & $9,14 \mathrm{~A}$ \\
\hline & $1 \mathrm{SA}$ & 7,56 & 8,13 & 8,67 & 9,67 & $8,51 \mathrm{~B}$ \\
\hline & $2 \mathrm{SA}$ & 7,56 & 7,99 & 8,33 & 9,06 & $8,23 \mathrm{~B}$ \\
\hline & Ortalama / Average & $7,56 \mathrm{C}$ & $8,37 \mathrm{~B}$ & $8,93 \mathrm{~B}$ & $10,33 \mathrm{~A}$ & ------- \\
\hline & LSD & \multicolumn{4}{|c|}{0,5795} & 0,5785 \\
\hline & $\begin{array}{l}\text { LSD p<0,05 } \\
\text { (UygXSüre) }\end{array}$ & \multicolumn{4}{|c|}{ Ö.D. } & \\
\hline
\end{tabular}

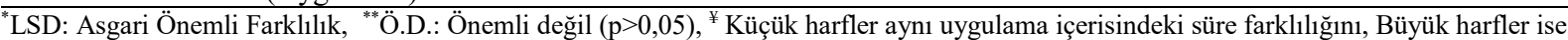
aynı süre içindeki uygulama farklılığını ortaya koymaktadır.

"LSD: Minimum Significant Difference, ${ }^{* *}$ Ö.D.: Not significant $(p>0.05),{ }^{*}$ Lowercase letters indicate time difference within the same application, and uppercase letters indicate the difference in application within the same period.

SÇKM değeri, muhafaza süresinin sonunda başlangıç değerine en yakın \%9,06 değeri ile $2 \mathrm{mM}$ SA uygulamasında ölçülmüştür.

Denemede "Roxana" kayısı çeşidine ait meyveler sert olum döneminde hasat edildiği için tat değeri başlangıçta nispeten düşük belirlenmişken, depolama süresi boyunca olgunlaşma ile bu değerlerde artış söz konusu olmuştur. Depolamanın sonuna doğru yaşlanma ile paralel olarak meyvelerde meydana gelen bozulmalar ile tekrar bir düşüş gerçekleşmiştir. Tat değerlerinde en etkili uygulama SA uygulamasının 2 mM'lık dozunda saptanmış (Çizelge 2). "Roxana" kayısı çeşidine ait meyveler hasat edildikten sonra, başlangıçta en yüksek dış 
görünüş değerine sahipken, bu değerde depolama süresi boyunca uygulamalara göre farkl1lı göstermekle beraber azalma gerçekleşmiştir. Olgunlaşma ile beraber meydana gelen bazı fizyolojik bozulmalar sebebiyle diş görünüş değerinde azalmalar söz konusu olmaktadır. Uygulama ortalamaları incelendiğinde en yüksek dış görünüş değeri 2,75 değeri ile $2 \mathrm{mM} \mathrm{SA}$ uygulamasında saptanmıştır (Çizelge 2).

Çizelge 2. "Roxana" kayısı çeşidine ait meyvelerde hasat sonrası SA uygulamalarının muhafaza süresi boyunca meyvelerde tat ve dış görünüş değerlerinin değişimlerine etkisi.

Table 2. The effect of postharvest SA applications on the changes in taste and appearance values of the fruits of the 'Roxana' apricot variety during the storage period.

\begin{tabular}{|c|c|c|c|c|c|c|}
\hline \multirow{9}{*}{$\begin{array}{l}\text { Tat değeri } \\
\text { Taste value }\end{array}$} & \multicolumn{6}{|c|}{$\begin{array}{l}\text { Duyusal değerlendirme } \\
\text { Sensory evaluation }\end{array}$} \\
\hline & $\begin{array}{l}\text { Uygulama } \\
\text { Application }\end{array}$ & $\begin{array}{l}\text { 0. Gün } \\
\text { Day } 0\end{array}$ & $\begin{array}{l}\text { 15. Gün } \\
\text { Day } 15\end{array}$ & $\begin{array}{l}\text { 30. Gün } \\
\text { Day } 30\end{array}$ & $\begin{array}{l}\text { 45. Gün } \\
\text { Day } 45\end{array}$ & $\begin{array}{l}\text { Ortalama } \\
\text { Average }\end{array}$ \\
\hline & Kontrol & $1,67 \mathrm{Ac}^{\ddagger}$ & $2,83 \mathrm{ABb}$ & $3,50 \mathrm{ABa}$ & $1,00 \mathrm{Cd}$ & $2,25 \mathrm{AB}$ \\
\hline & $0.5 \mathrm{SA}$ & $1,67 \mathrm{Ac}$ & $2,33 \mathrm{Bb}$ & $3,67 \mathrm{Aa}$ & $1,00 \mathrm{Cd}$ & $2,17 \mathrm{~B}$ \\
\hline & $1 \mathrm{SA}$ & $1,67 \mathrm{Ac}$ & $3,17 \mathrm{Aa}$ & $2,33 \mathrm{Bb}$ & $1,33 \mathrm{Bc}$ & $2,13 \mathrm{~B}$ \\
\hline & $2 \mathrm{SA}$ & $1,67 \mathrm{Ac}$ & $2,33 \mathrm{Bbc}$ & $4,00 \mathrm{Aa}$ & $3,00 \mathrm{Aab}$ & $2,75 \mathrm{~A}$ \\
\hline & $\begin{array}{l}\text { Ortalama } \\
\text { Average }\end{array}$ & $1.67 \mathrm{C}$ & $2.67 \mathrm{~B}$ & $3.38 \mathrm{~A}$ & $1.58 \mathrm{C}$ & $\ldots$ \\
\hline & $\mathrm{LSD}^{*}$ & \multicolumn{4}{|c|}{0.5277} & 0.5277 \\
\hline & LSD $p<0,05$ (UygXSüre) & \multicolumn{5}{|c|}{0.679} \\
\hline \multirow{8}{*}{$\begin{array}{l}\text { Diş görünüş̧ } \\
\text { değeri } \\
\text { Appearance } \\
\text { value }\end{array}$} & $\begin{array}{l}\text { Uygulama } \\
\text { Application }\end{array}$ & $\begin{array}{l}0 . G u ̈ n \\
\text { Dav } 0\end{array}$ & 15. Gün & 30. Gün & 45. Gün & $\begin{array}{l}\text { Ortalama } \\
\text { Average }\end{array}$ \\
\hline & Kontrol & $9,00 \mathrm{Aa}$ & $7,67 \mathrm{Aa}$ & $4,00 \mathrm{Cb}$ & $1,33 \mathrm{Bc}$ & $5,50 \mathrm{C}$ \\
\hline & $0.5 \mathrm{SA}$ & $9,00 \mathrm{Aa}$ & $8,67 \mathrm{Aa}$ & $6,33 \mathrm{ABb}$ & $3,00 \mathrm{Ac}$ & $6,75 \mathrm{AB}$ \\
\hline & $1 \mathrm{SA}$ & $9,00 \mathrm{Aa}$ & $8,33 \mathrm{Aa}$ & $5,00 \mathrm{BCb}$ & $2,67 \mathrm{ABc}$ & $6,25 \mathrm{~B}$ \\
\hline & $2 \mathrm{SA}$ & $9,00 \mathrm{Aa}$ & $9,00 \mathrm{Aa}$ & $7,00 \mathrm{Ab}$ & $3,83 \mathrm{Ac}$ & $7,21 \mathrm{~A}$ \\
\hline & Ortalama Average & $9,00 \mathrm{~A}$ & $8,42 \mathrm{~A}$ & $5,58 \mathrm{~B}$ & $2,71 \mathrm{C}$ & 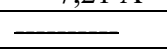 \\
\hline & LSD & \multicolumn{4}{|c|}{0,654} & 0,654 \\
\hline & LSD p<0,05 (UygXSüre) & & & 1,1821 & & \\
\hline
\end{tabular}

${ }^{*}$ LSD: Asgari Önemli Farklılık, ${ }^{*}$ Küçük harfler aynı uygulama içerisindeki süre farklılığını, Büyük harfler ise aynı süre içindeki uygulama farklılı̆ııı ortaya koymaktadır.

${ }^{*}$ LSD: Minimum Significant Difference, ${ }^{*}$ Lowercase letters indicate time difference within the same application, and uppercase letters indicate the difference in application within the same period.

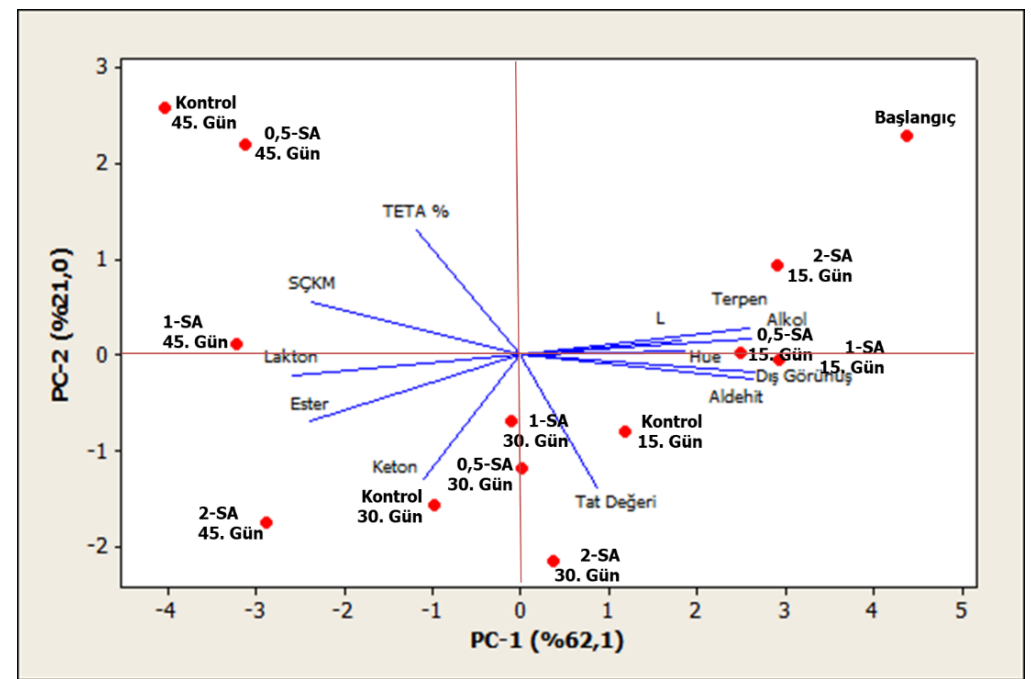

Şekil 1. Aroma bileşen grupları ile titre edilebilir toplam asitlik, suda çözünür katı madde miktarı, meyve kabuk rengi $\left(\mathrm{L}^{*}\right.$, hue $\left.{ }^{\circ}\right)$ ve duyusal değerlendirme arasındaki ilişkinin incelendiği biplot grafiğgi.

Figure 1. Biplot plot examining the relationship between aroma component groups, total titratable acidity, soluble solid content fruit skin color ( $\mathrm{L}^{*}$, hueo), and sensory evaluation. 
Araştırma kapsamında aroma bileşen gruplarının ve kalite değerlerinin birbirleriyle ilişkilerinin daha rahat incelenebilmesi amaciyla biplot grafikleri kullanılmıştır (Şekil 1)

Biplot bilgi analizlerinde kullanışı bir araç olup büyük bilgi matrislerinde görsel değerlendirme sağlamaktadır. Biplot birimler arası uzaklıkları gösterebilmekte ve birimleri korelasyon değerlerini kullanarak gruplandırabilmektedir (Gabriel, 1971).

Şekil 1'de görüldüğü üzere SÇKM ve TEA değerleri Kontrol ve 0,5 mM SA uygulamalarının 45. gün muhafaza süreleriyle aynı eksende, $L^{*}$ ve $\mathrm{Hue}^{\mathrm{o}}$ değerleri ile de zit eksende ( $\left.\mathrm{PC} 1>0 ; \mathrm{PC} 2>0\right)$ yer almaktadır. SÇKM ve TEA değerleri bakımından en yüksek değerler bu iki uygulama-süre kombinasyonunda elde edilmiştir. Diğer bir kalite kriteri olan tat değeri incelendiğinde ise 30. gün muhafaza süresi ile aynı yönde ve çok yakın olduğu ayrıca bu muhafaza süre ile pozitif korelasyonda olduğu gözlenmektedir.

$1 \mathrm{mM}$ SA ve $2 \mathrm{mM} \mathrm{SA}$ uygulamalarının 45. gün muhafaza süreleri ile Kontrol ve 0,5 SA uygulamalarının 30. gün muhafaza süreleri aynı eksende yer almaktadır $(\mathrm{PC} 1>0 ; \quad \mathrm{PC} 2<0) . \quad \mathrm{Bu}$ eksende lakton, ester ve keton bileşen gruplarının da yer aldığı saptanmıştır. Bu bulgular ile $1 \mathrm{mM}$ $\mathrm{SA}$ ve $2 \mathrm{mM} \mathrm{SA}$ uygulamalarının 45 . gün depolama süresi ile Kontrol ve $0,5 \mathrm{mM}$ SA uygulamalarının 30. gün depolama süresinde "Roxana" kayısı meyvelerinin lakton, ester ve ketonlar bakımından daha zengin olduğunu; buna karşın $1 \mathrm{mM}$ SA ve $2 \mathrm{mM}$ SA uygulamalarının 15 . gün depolama süresinin bu eksenin tam tersinde yer aldığı yani bu bileşen grupları bakımından en düşük içeriğe sahip olan meyveleri barındırdığı söylenebilmektedir $(\mathrm{PC} 1<0 ; \mathrm{PC} 2>0)$.

Tüm uygulamaların 15 günlük muhafaza süreleri ile $\mathrm{L}, \mathrm{Hue}^{\mathrm{o}}$ ve dış görünüş değeri aynı eksende yer almaktadır. Şekilde görülen biplot grafiğinde 1 mM SA ve 0,5 mM SA uygulamalarının 15 günlük depolama süresinde terpen, alkol ve aldehit gruplarının daha yoğun olduğu, buna karşın özellikle $1 \mathrm{mM}$ SA uygulamasının 45 günlük depolama süresinde bu bileşen gruplarının en düşük düzeyde bulunduğu gözlenmektedir.

Yukarıda bahsi geçen biplot grafiğinde ayrıca bileşen gruplarının birbirleriyle ilişkileri de belirlenmektedir. Terpen, alkol ve aldehit gruplarının birbirleriyle aynı yönde ve çok yakın olması bu bileşen gruplarının tüm uygulamaların her muhafaza süresinde birbirleriyle yakın ilişkide olduğu ve pozitif korelasyon içerdiği gözlenmektedir. Ayrıca bu bileşenlerin lakton, ester aroma grupları ve SÇKM miktarı ile negatif korelasyonda bulunduğu da tespit edilmiștir. Benzer şekilde lakton, ester ve aroma gruplarıyla SCCKM miktarı da kendi aralarında pozitif korelasyona sahiptir.

Ticari olum dönemine ait meyvelerde yapılan ölçümlerde aldehit bileşenlerinin yüksek miktarlarda olduğu belirlenmiş, ancak olgunluğun ilerlemesiyle azaldığı gözlenmiştir. Aldehit aroma bileșen grubuna ait, (Z)-3-Hekzenal bileşiğinin başlangıçtaki 17,4 $\mu \mathrm{g} / \mathrm{kg}$ değeri olgunluğun ilerlemesi ile azalmış ve 45. gün tüm uygulamalarda tamamen kaybolmuştur (Çizelge 3). Karabulut ve ark. (2018), kayısının farklı olgunluk dönemlerinde aroma bileșenlerini araştırdıkları bir çalışmada da (Z)-3-Hekzenal bileşeninde, olgunluğun ilerlemesiyle beraber azalmanın gerçekleştiğini bildirmişlerdir. Hekzanal bileşiğinin de başlangıçta $281,3 \mu \mathrm{g} / \mathrm{kg}$ olan değeri (Z)-3-Hekzenal bileşiğinde olduğu gibi, Kontrol ve $0.5 \mathrm{mM}$ SA uygulamasında son dönemde kaybolmuş, $1 \mathrm{mM}$ ve $2 \mathrm{mM}$ SA uygulamalarında az oranda (surasıyla 12,7-51,3 $\mu \mathrm{g} / \mathrm{kg}$ ) tespit edilmiştir (Çizelge 3). Son dönemde Kontrol ve 0,5 mM SA uygulamalarında görülmeyip, $1 \mathrm{mM}$ SA ve $2 \mathrm{mM}$ SA uygulamalarında görülmesi, olgunluğun $1 \mathrm{mM}$ ve $2 \mathrm{mM}$ SA uygulamalarında diğer uygulamalara göre daha yavaş ilerlemesinden kaynaklanmaktadır. Benzaldehit, (E)-2-Hekzenal aldehitleri yine 15. günde azalmaya başlayıp son döneme kadar azalma eğiliminde olmuştur. Bu azalma eğilimi en yüksek Kontrol uygulamasında olmak üzere, sırasıyla 0,5 mM, $1 \mathrm{mM}$ ve $2 \mathrm{mM}$ SA uygulamalarında doz artışıyla ters orantılı bir şekilde ilerlemiştir. Son dönemde en yüksek değer olgunlaşmanın yavaş ilerlemesi ile $2 \mathrm{mM}$ SA uygulamasinda tespit edilmiştir (Çizelge 3). Yine kayısının farklı 
olgunluk dönemlerindeki aroma bileşenlerin incelendiği başka bir çalışmada (E)-2-Hekzenal bileşiğinin olgunlukla beraber azaldığı bildirilmiştir (González-Agüero ve ark., 2009). Hasattan sonra erken olgunluk döneminde olan 'Roxana"' kayıs1 meyvelerinde Hekzanal $(281,3 \mu \mathrm{g} / \mathrm{kg})$ ve E-2Hekzenal $(185,6 \mu \mathrm{g} / \mathrm{kg})$ bileşikleri majör öneme sahip bileşenler olup, olgunluğun ilerlediği safhalarda miktarlarının azalmasına karşın aldehit grubunda hala önemli bileşenlerdir (Çizelge 3). Ayrıca çimensi ve elma benzeri ya da acı badem ve yeşil buruk hissi uyandırdığı belirtilen E-2-hekzenal bileşiğinin tersine, hekzanal aromatik bileşeninin az oranda olması halinde çimensi, tatlı bir aroma algısı oluşturduğu, bunun aksine yüksek oranda bulunduğunda ise yeşil bir aroma algisı oluşturduğu bildirilmiştir (Reiners ve Grosch, 1998; Aparicio ve Luna, 2002; Morales ve ark., 2005).

Alkollerden başlangıçta sırasıyla $225,1 \mu \mathrm{g} / \mathrm{kg}$ ve $221,7 \mu \mathrm{g} / \mathrm{kg}$ olan Hekzanol ve E-2-Hekzenol bileşenleri olgunluğun ilerlemesiyle birlikte azalmış ve bu azalma da en fazla kontrol uygulamasinda gerçekleşmiştir. Kontrol uygulamasında son dönemde sirasiyla $26,2 \mu \mathrm{g} / \mathrm{kg}$ ve $37,9 \mu \mathrm{g} / \mathrm{kg}$ değerleri bulunmuştur. $2 \mathrm{mM}$ SA uygulamasında azalma oranı diğer uygulamalara kıyasla daha yavaş olmuştur ve muhafaza süresinin son döneminde Hekzanol bileşiği $61,9 \mu \mathrm{g} / \mathrm{kg}$, E-2Hekzenol bileşiği ise $73,2 \mu \mathrm{g} / \mathrm{kg}$ değerinde tespit edilmiştir (Çizelge 3). González-Agüero ve ark. (2009), yapmış oldukları çalışmada kayısıda olgunluğun ilerleyen dönemlerinde bu bileşiklerin azaldığını bildirmişlerdir. 2-Propanol ve 1-Butanol değerleri yeşil olum döneminde hasadı yapılan kayısılarda tespit edilmeyip, muhafaza süresinin 15. gününden sonra ortaya çıkmıştır ve olgunluğun ilerleyen dönemlerinde artmaya devam etmiştir. Etanol bileşiği de bu bileşenlerin aksine başlangıçta da var olup, yine olgunlukla beraber artış göstermiştir. Karabulut ve ark. (2018), yaptıkları çalışmada bulgularımızla benzer sonuçlar ortaya koymuşlardır. Genel anlamda çalışma sonuçlarında,
1 ve $2 \mathrm{mM}$ SA uygulamalarının istenmeyen alkol bileşenlerinin sentezini engellediği görülmüştür.

Ester grubu bileşenleri incelendiğinde hasattan sonra yapılan başlangıç analizlerinde $332,1 \mu \mathrm{g} / \mathrm{kg}$ değeri ile Hekzil asetat bileşiği diğer ester bileşenlerine göre ön plana çıkmaktadır. Olgunluğun ilerlemesiyle birlikte miktarında artış gerçekleşmiştir. Muhafaza süresinin 15. gününe kadar olgunluğun hızlı ilerlemesi nedeniyle en yüksek oran 472,8 $\mu \mathrm{g} / \mathrm{kg}$ değeri ile Kontrol uygulamasında görülmüş ve sirasiyla $0,5-1$ ve $2 \mathrm{mM}$ SA uygulamalarında $458,5,439,3,423 \mu \mathrm{g} / \mathrm{kg}$ değerleri tespit edilmiştir. 30 günlük depolamanın sonunda Kontrol uygulamasında meydana gelen hızlı olgunlaşma bu aroma bileşenini baskılamış ve bununla paralel olarak Kontrol uygulamasında çıkan Hekzil asetat oran1 da baskılanmıştır. 30 günlük depolama sonunda en yüksek değer $539,5 \mu \mathrm{g} / \mathrm{kg}$ değeri ile 2 mM SA uygulamasında tespit edilmiştir (Çizelge 3). Hekzil asetat bileşiği kayısının tipik aroma bileşenleri ile en iyi korelasyonu gösteren ve kayısı aromasına katkı sağlayan bir bileşik olarak tanımlanmaktadır (Guichard ve ark., 1990). Aldehitler, olgunlaşmanın ilerlemesiyle meyvelerde alkollere ve esterlere dönüştürüldüğü bildirilmiştir (Fellman ve Mattheis, 1995; González-Agüero ve ark., 2009). Çalışmamızda da muhafaza süresinin artmas1 ile aldehit gruplarında azalış ve bunun aksine ester ve alkol gruplarında ise artış gerçekleștiği görülmektedir. Diğer ester bileşenlerinden Metil asetat, Butil asetat, Metil butanoat bileşenleri muhafaza süresinin artması ile doğru orantılı olarak artış gerçekleştirmiştir, fakat 30 günlük depolamadan sonra bir azalma dönemine girmiştir. $\mathrm{Bu}$ durumun yukarıda da bahsedildiği gibi alkol bileşenlerindeki artış ile ester bileşenlerinin baskılanmasından ileri geldiği düşünülmektedir. Uygulama olarak ele alındığında ise her iki ester bileşeninde de $1 \mathrm{mM}$ SA ve $2 \mathrm{mM}$ SA uygulamalarında, 45. günde bile artış devam etmektedir (Çizelge 3). Bu uygulama dozlarının olgunluğu yavaşlatmasıyla orantılı olarak alkol bileşenlerinin sentezlenmesini yavaşlatmasından kaynaklanmaktadır. 


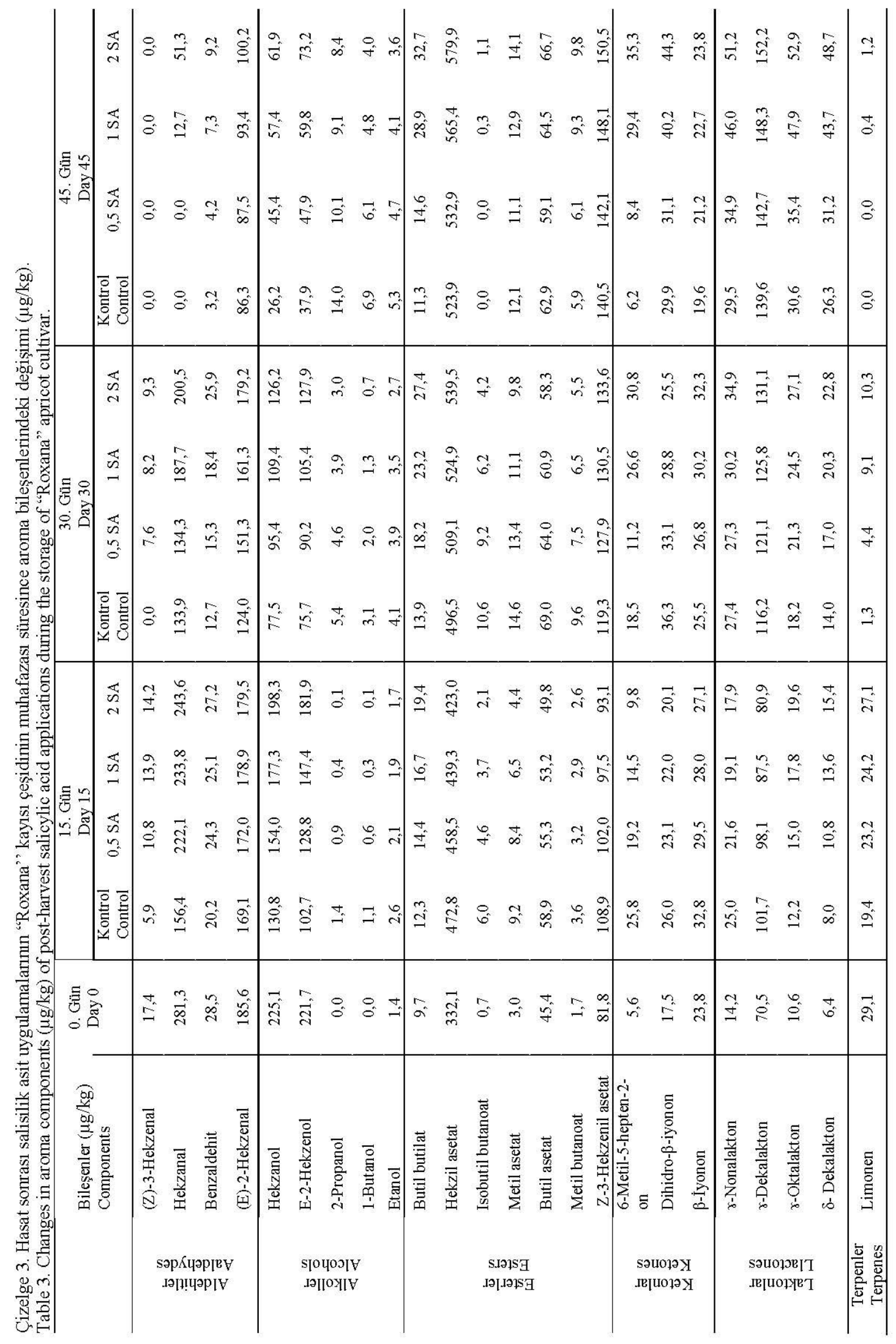


El Hadi ve ark. (2013) göre, ketonların çoğu, karotenoid parçalama dioksijenaz enzimleri tarafindan karotenoidlerden sentezlenir. Kayıs1 meyveleri bilindiği gibi klimakterik meyve grubunda yer aldığı için hasat sonrası olgunlaşmaya devam etmekte ve optimum hasat zamanındaki meyve zemin rengi zamanla tipik kayısıya özgü renge dönüşmektedir. Çalışmamızda olgunluğun ilerleyen dönemlerinde genel anlamda keton bileşenlerinde önce bir artış ve 30 günlük depolamadan sonra ise azalma meydana gelmiştir. Olgunluğun ilerlemesiyle birlikte meyve zemin renginin sar1-turuncudan, turuncu-kırmızıya dönüşü ve dolayısıyla karoten parçalanması gerçeklemiştir. Bilindiği gibi karotenoid içeriği enzimatik bozulma ile değişebilmektedir (Radi ve ark., 1997). Keton bileşenlerinden 6Metil-5-hepten-2-on ve Dihidro-b-iyonon bileşiklerinde de önce bir artış ve 30 . günden sonra azalma söz konusu olmuştur. Ancak $1 \mathrm{mM}$ SA ve 2 mM SA uygulamalarında 45. günde de artış eğilimi devam etmiştir (Çizelge 3). Bu durum, her iki uygulamanın da olgunluk seviyesini Kontrol grubu ve $0,5 \mathrm{mM}$ SA uygulamasına göre yavaşlatmasından ileri gelmektedir.

Lakton grubu bileşenleri kayısının tipik aroması ile ilişkilendirilmektedir. $\mathrm{Bu}$ bileşenler arasında niceliksel olarak en önemlilerinin $\gamma$-oktalakton, $\gamma$ dekalakton bileşenleri olduğu bildirilmiştir (Gómez ve ark., 1997). Çalışmamızda da ticari olum döneminde hasadı yapılan kayısı meyvelerinde muhafaza öncesinde lakton bileşenleri düşük oranda tespit edilmiştir. Olgunluğun ilerlemesi ve kayısıya özgü tadın oluşmasıyla birlikte lakton bileşenlerinin oranı artmıştır. Denemede lakton bileşenlerinin arasında oransal olarak $\gamma$-oktalakton bileşeni dikkat çekmektedir. Muhafaza süresinin 15. gününde en yüksek değer Kontrol uygulamasında tespit edilmiş ve uygulama dozunun artışı ile lakton miktarındaki artış ters orantı göstermiştir
(Çizelge 3). Olgunluğun ilerlemesiyle Kontrol grubunda meydana gelen hızlı olgunlaşma ve alkol bileşenlerindeki artışla beraber kayısının tipik aromas1 baskılanmış ve 30 günlük muhafaza periyodunda uygulamaların etkisi ön plana çıkmış ve $2 \mathrm{mM}$ SA uygulaması kayısı meyvelerinin karakteristik aroma bileşenlerinin sentezinin olması gereken düzeyde sentezlenmesine katkı sağlamıştır.

Bir terpenoid hidrokarbon olan limonenin, meyve aromasının meyvemsi ve narenciye karakterinden sorumlu olduğu bildirilmiştir (Guillot ve ark. 2006). Sert olum döneminde hasad1 yapılan meyvelerde başlangıçta yüksek oranda tespit edilen bu bileşik olgunluğun ilerlemesiyle azalma eğilimi göstermiş ve son dönemde Kontrol ve $0,5 \mathrm{mM} \mathrm{SA}$ uygulamasında kaybolmuştur. $1 \mathrm{mM} \mathrm{SA}$ ve $2 \mathrm{mM}$ SA uygulamalarında da son dönemde çok düşük oranda tespit edilmiştir (Çizelge 3).

\section{SONUÇ}

Çalışma sonucunda "Roxana" kayısı çeşidine ait meyvelerin aromasına katkı sağlamada en iyi uygulama olarak $2 \mathrm{mM}$ SA uygulaması ön plana çıkmış ve meyvelerin olgunlaşma hızını diğer uygulamalara göre yavaşlatmıştır. Muhafaza süresi boyunca yapılan analizlerde aldehitler, esterler, ketonlar, laktonlar, alkoller ve terpenler olmak üzere altı aromatik bileşen grubu tespit edilmiştir. Lakton ve ester grubu bileşenleri kayısı meyvelerinin karakteristik aromasına katkı sağlayan bileşen gruplarıdır. 1 ve $2 \mathrm{mM}$ SA uygulamaları kayıs1 meyvelerinin karakteristik aroma bileşenlerinin sentezinin olmas1 gereken düzeyde sentezlenmesine katkı sağlamıştır. Bu uygulamalar olgunlaşmayı ve bununla paralel olarak meyvelerin bozulmasinı ve meyvelerde alkol bileşenlerinin yoğun olarak sentezlenmesini engellediği için, kayısının karakteristik aroma bileşenlerinin oluşmasında etkili olmuştur. 


\section{LITERATÜR LISTESI}

Aubert, C., and C. Chanforan. 2007. Postharvest changes in physicochemical properties and volatile constituents of apricot (Prunus armeniaca L.). Characterization of 28 cultivars. Journal of agricultural and food chemistry. 55(8): 3074-3082.

Anonim 2019. Food and Agriculture Organization of United Nations (FAO) Datas http://www.fao.org/faostat/en/ \#data/QCL (Erișim tarihi 22.08.2021).

Anonim 2020. Türkiye İstatistik Kurumu Verileri https://biruni.tuik.gov.tr/medas $/$ kn $=92 \&$ locale $=\operatorname{tr}$ (Erişim tarihi 22.08.2021).

Anonymous 1998. Minolta, Precise Color Communication, Color Control from Perception to Instruments. Minolta Co. Ltd., Radiometric Ins. Ope., Osaka, Japan, 59p.

Aparicio, R., and G. Luna. 2002. Characterisation of monovarietal virgin olive oils. Eur. J. Lipid Sci. Technol. 104 (9-10): 614-627.

Asma, B. M. 2000. Kayısı yetiştiriciliği. s.2. ed: Hüseyin E. Evin Ofset, Malatya.

Asma, B. M., T. Kan, O. Birhanlı ve A. Erdoğan. 2006. Geç Olgunlaşan Sofralık Kayısıların Melezleme Yoluyla Islahı (I. Dilim). TÜBİTAK Proje No: TOGTOG3099. Nisan 2006, Malatya.

Baldwin, E. 2002. Fruit flavor, volatile metabolism and consumer perceptions. pp. 89-106. In: M. Knee (Ed). Fruit Quality and Its Biological Basis. Sheffield Academic Press Ltd. Mansion House. UK.

Beattie, B., and N. Wade. 1996. Storage, ripening and handling of fruit. pp. 40-69In: In Fruit Processing. Springer, Boston, MA

Çalhan, Ö. 2010. Bazı depolama koşullarının Roxana kayısı çeşidinin soğukta muhafazası üzerine etkileri. Yüksek lisans tezi. Süleyman Demirel Üniversitesi Fen Bilimleri Enstitüsü Bahçe Bitkileri Anabilim Dalı. Isparta.

Defilippi, B. G., D. Manriquez, K. Luengwilai, and M Gonzalez-Aguero. 2009. Aroma volatiles: Biosynthesis and mechanisms of modulation during fruit ripening. Ad. Bot. Res. 50: 1-37

Dundar, O., A. B. Kuden, and F. G. Dennis. 1997 Investigations on cold storage and post harvest physiology of J. H. Hale Peach. Acta Hortic 441: 411441

El Hadi, M. A. M., F. J. Zhang, F. F., Wu C. H., Zhou, and J. Tao. 2013. Advances in fruit aroma volatile research. Molecules, 18(7): 8200-8229.

Erbaş, D., C. Onursal ve M. A. Koyuncu. 2015. Derim sonras1 salisilik asit uygulamasının Aprikoz kayısı çeşidinin soğukta depolanması üzerine etkileri. Meyve Bilimi 2(2): 50-57.

Fellman J. K., and J. P. Mattheis 1995. Ester biosynthesis in relation to harvest maturity and controlled atmosphere storage of apples. 149-163.
Fidan, Y., ve G. Söylemezoğlu. 1995. Bahçe bitkilerinin hasat sonras1 fizyolojisi açısından etilenin önemi. Biyosentezi ve İşleyiş Mekanizması. GIDA, 20(1).

Gabriel, K. R. 1971. The biplot graphic display of matrices with application to principal component analysis. Biometrika 58(3): 453-467.

Gokbulut, I., and I. Karabulut. 2011. SPME-GC-MS detection of volatile compounds in apricot varieties. Food Chem. doi:10.1016/J. Food Chem.2011.11.080.

Gómez, E., and C. A. Ledbetter. 1997. Development of volatile compounds during fruit maturation: characterization of apricot and plum $\times$ apricot hybrids. Journal of the Science of Food and Agriculture 74(4): 541-546.

González-Agüero, M., S. Troncoso, O. Gudenschwager, R. Campos-Vargas, M. A. Moya-León, and B. G. Defilippi. 2009. Differential expression levels of aroma-related genes during ripening of apricot (Prunus armeniaca L.). Plant physiology and biochemistry 47(5): 435-440

Guichard, E., P. Schlich, and S. Issanchou, 1990. Composition of apricot aroma: correlations between sensory and instrumental data. Journal of Food Science 55(3): 735738.

Guillot, S., L. Peytavi, S. Bureau, R. Boulanger, J. P. Lepoutre, J. Crouzet, and S. Schorr-Galindo. 2006. Aroma characterization of various apricot varieties using headspace-solid phase microextraction combined with gas chromatography-mass spectrometry and gas chromatography-olfactometry. Food Chemistry 96(1): 147-155.

Karabulut, I., I. Gokbulut, T. Bilenler, K. Sislioglu, I. S. Ozdemir, B. Bahar, and F. Seyhan 2018. Effect of fruit maturity level on quality, sensory properties and volatile composition of two common apricot (Prunus armeniaca L.) varieties. Journal of food science and technology 55(7): 2671-2678.

Martinez-Romero, D., G. Bailén, M. Serrano, F. Guillén, J. M. Valverde, P. Zapata, and D. Valero 2007. Tools to maintain postharvest fruit and vegetable quality through the inhibition of ethylene action: a review. Critical reviews in food science and nutrition 47(6): 543-560.

Morales M.T., G. Luna and R. Aparicio 2005. Comparative study of virgin olive sensory defects. Food Chemistry, 91: 293-301.

Özbek, S. 1978. Özel Meyvecilik. Çukurova Ü. Ziraat Fak. Yayınları. No: 128. Adana.

Özdemir, A. E., E. Ertürk, M. Çelik, R. Dilbaz 2006. Venüs nektarin çeşidinin soğukta muhafazası. Tekirdağ Ziraat Fakültesi Dergisi 3(3):297-304.

Özeker, E. 2005. Salisilik asit ve bitkiler üzerindeki etkileri. Ege Üniversitesi Ziraat Fakültesi Dergisi 42(1), 213223 . 
Özkaya, O., Ö. Dündar ve A. Küden. 2005. Adana koşullarında yetiştirilen angeleno erik çeşidinin muhafaza performansı. III. Bahçe Ürünlerinde Muhafaza ve Pazarlama Sempozyumu. AntakyaHatay. s. 406-408.

Perez A., J. Rios, C. Sanz, and J. Olias. 1992. Aroma components and free amino acids in strawberry variety Chandler during ripening. J Agric Food Chem 40 2232È2235.

Radi, M., M. Mahrouz, A. Jaouad, M. Tacchini, S. Aubert, M. Hugues, and M. J. Amiot. 1997. Phenolic composition, browning susceptibility, and carotenoid content of several apricot cultivars at maturity. HortScience. 32: 1087-1091.

Reid, M. S. 1992. Maturation and maturity indices. pp. 21-28. In: J. H. La Rue, R. S. Johnson (Eds) Peaches, Plums and Nectarines: Growing and Handling for Fresh Market. University of California Department of Agriculture and Natural Resources Publication No. 3331.

Reiners J., and W. Grosch. 1998. Odorants of virgin olive oils with different flavor profiles. J. Agric. Food Chem. 46 (7):2754-2763.
Sakaldaş, M. 2012. Çanakkale yöresinde yetiştirilen California Wonder biber tipinde farkl1 hasat sonrası uygulamaların kaliteye etkileri. Doktora tezi. Çanakkale Onsekiz Mart Üniversitesi Fen Bilimleri Enstitüsü Bahçe Bitkileri Anabilim Dalı. Çanakkale.

Seker, M., E. Gur, N. Ekinci, and M. A. Gundogdu. 2018. Volatile constituents of different apricot varieties in cool subtropical climate conditions. Horticult Int J, 2(5): 237-242.

Srivastava, M. K., and U. N. Dwivedi. 2000. Delayed ripening of banana fruit by salicylic acid. Plant Science 158(12):87-96.

Şeker, M., E. Gür, N. Ekinci, and M. A. Gündoğdu. 2012. Comparison of white nectarines grown in Çanakkale conditions with standard peach, nectarine, apricot and plum varieties for aromatic compounds. International Agriculture, Food and Gastronomy Congress. 15-19 February 2012. Antalya-Turkey. s 160-161. OP-C03.2:1-9.

Yaşar, A. 2017. Kirazda hasat sonrası salisilik asit uygulaması ve modifiye atmosfer paketlemenin muhafaza süresi ve kalite üzerine etkileri. Yüksek lisans tezi. Selçuk Üiversitesi Fen Bilimleri Enstitüsü Bahçe Bitkileri Anabilim Dalı. Konya. 